\title{
Familial Mediterranean fever, Inflammation and Nephrotic Syndrome: Fibrillary Glomerulopathy and the M680I Missense Mutation
}

\author{
Patrick W Fisher*1, L Tammy Ho², Robert Goldschmidt ${ }^{3}$, \\ Ronald J Semerdjian ${ }^{4}$ and Gregory W Rutecki ${ }^{5}$
}

Address: ${ }^{1}$ Department of Medicine, Department of Graduate Medical Education, Northwestern University Feinberg School of Medicine, Evanston Northwestern Healthcare, Evanston, IL, USA, ${ }^{2}$ Department of Medicine, Division of Nephrology, Northwestern University Feinberg School of Medicine, Evanston Northwestern Healthcare, Evanston, IL, USA, ${ }^{3}$ Department of Pathology, Northwestern University Feinberg School of Medicine, Evanston Northwestern Healthcare, Evanston, IL, USA, ${ }^{4}$ Department of Medicine, Division of Pulmonary Diseases, Northwestern University Feinberg School of Medicine, Evanston Northwestern Healthcare, Evanston, IL, USA and ${ }^{5}$ Department of Medicine, Northwestern University Feinberg School of Medicine, Evanston Northwestern Healthcare, Evanston, IL, USA

Email: Patrick W Fisher* - pfisher002@md.northwestern.edu; L Tammy Ho - ltho@enh.org; Robert Goldschmidt - rgoldschmidt@enh.org; Ronald J Semerdjian - resemerdjian@enh.org; Gregory W Rutecki - grutecki@enh.org

* Corresponding author

Published: II August 2003

BMC Nephrology 2003, 4:6

This article is available from: http://www.biomedcentral.com/l47/-2369/4/6

(C) 2003 Fisher et al; licensee BioMed Central Ltd. This is an Open Access article: verbatim copying and redistribution of this article are permitted in all media for any purpose, provided this notice is preserved along with the article's original URL.

\begin{abstract}
Background: Familial Mediterranean fever (FMF) is an autosomal recessive disease characterized by inflammatory serositis (fever, peritonitis, synovitis and pleuritis). The gene locus responsible for FMF was identified in 1992 and localized to the short arm of chromosome 16. In 1997, a specific FMF gene locus, MEFV, was discovered to encode for a protein, pyrin that mediates inflammation. To date, more than forty missense mutations are known to exist. The diversity of mutations identified has provided insight into the variability of clinical presentation and disease progression.
\end{abstract}

Case Report: We report an individual heterozygous for the M680I gene mutation with a clinical diagnosis of FMF using the Tel-Hashomer criteria. Subsequently, the patient developed nephrotic syndrome with biopsy-confirmed fibrillary glomerulonephritis (FGN). Further diagnostic studies were unremarkable with clinical workup negative for amyloidosis or other secondary causes of nephrotic syndrome.

Discussion: Individuals with FMF are at greater risk for developing nephrotic syndrome. The most serious etiology is amyloidosis (AA variant) with renal involvement, ultimately progressing to endstage renal disease. Other known renal diseases in the FMF population include IgA nephropathy, IgM nephropathy, Henoch-Schönlein purpura as well as polyarteritis nodosa.

Conclusion: To our knowledge, this is the first association between FMF and the M680I mutation later complicated by nephrotic syndrome and fibrillary glomerulonephritis.

\section{Background}

Familial Mediterranean Fever (FMF) is an autosomal recessive disease primarily affecting individuals of Arme- nian, Turkish, Arab, and Jewish origin [1]. The disease is characterized by recurrent episodes of fever, pleuritis, peritonitis, synovitis, and pericarditis [2-4]. The most serious 
complication of FMF is the development of amyloidosis (AA variant), leading to nephrotic syndrome and endstage renal disease [4]. Amyloidosis remains the leading cause of FMF-related mortality in affected individuals not receiving colchicine prophylaxis [5]. Additionally, other non-amyloid renal diseases are reported to occur in the FMF population with variable prevalence; for example, IgA and IgM nephropathy, and vasculitides including both polyarteritis nodosa (PAN) and Henoch-Schonlëin purpura [6]. Differentiation of the underlying renal disease in FMF patients who present with nephrotic syndrome is difficult, often requiring further diagnostic studies to identify the etiology. Moreover, the identification of the etiology of nephrotic syndrome is critical in determining an effective treatment regimen. For example, patients with amyloidosis (AA variant) usually respond to oral colchicine, which is known to prevent the insidious onset of end-stage renal disease [5]. In contrast, patients with PAN or Henoch-Schonlëin purpura usually respond very well to corticosteroids, with some experiencing complete resolution of proteinuria. [6]

In 1992, the gene responsible for Familial Mediterranean Fever (FMF), MEFV, was found to reside on the short arm of chromosome 16 [7]. Five-years later, the MEFV gene locus was discovered to encode for a protein, pyrin (marenostrin), a member of the RoRet gene family $[8,9]$. Pyrin is known to play a role in mitigating an inflammatory response $[8,10]$. To date, more than forty missense mutations are noted in association with FMF. One specific mutation, M694V, has been implicated as a risk factor for amyloidosis, especially in North African Jews homozygous for the M694V missense mutation [11]. However, individuals with mutations other than M694V are known to develop amyloidosis with renal involvement [11]. For the first time, we report an individual with symptomatic FMF, heterozygous for the M680I missense mutation, who developed progressive proteinuria, hematuria, and subsequent nephrotic syndrome secondary to fibrillary glomerulonephritis.

Table I: MEFV missense mutations evaluted in our patient

\begin{tabular}{ll}
\hline Exon 2 & Exon 10 \\
\hline EI48Q & M680I \\
& M694V \\
& M694I \\
& 692 dell \\
& LS95R \\
& A744S \\
& V726A
\end{tabular}

* Analysis performed at the UCLA Medical Center using Polymerase Chain Reaction

\section{Case Report}

A forty-nine year-old American man of Armenian ancestry was diagnosed clinically with Familial Mediterranean Fever (FMF) at age 39. At that time, he presented with recurrent, episodic fevers, peritonitis, synovitis, and pleuritis. Since the initial diagnosis, his treatment consisted of oral colchicine $(1.2 \mathrm{mg} /$ day $)$, resulting in a decrease in the frequency, duration, and intensity of his inflammatory episodes. However, over the subsequent decade, his inflammatory episodes became more frequent, occurring every 7-10 days, with an average duration of approximately 3 days. His symptoms consisted of diffuse abdominal pain, sharp, non-radiating chest pain, and fevers as high as 103 degrees F. An extensive workup for other etiologies responsible for febrile illness was unremarkable (e.g. infection, malignancy, connective tissue disorders). Upon further examination, the previous diagnosis of FMF was confirmed using the Tel-Hashomer criteria [12].

Despite an increase in the oral colchicine dose to $1.8 \mathrm{mg} /$ day, his symptoms persisted, prompting further diagnostic studies to correlate the clinical diagnosis with genotype. A serum sample was sent to the UCLA Medical Center for genetic analysis. Polymerase chain reaction, testing for the nine most common mutations [Table 1], was performed by methods previously described [13]. The results demonstrated the presence of an MEFV missense mutation (M680I) on one allele. Several months later, he presented with complaints of lower extremity edema without associated symptoms of cough, shortness of breath, dyspnea on exertion, orthopnea, paroxysmal nocturnal dyspnea, or chest pain. Upon further questioning, the patient admitted to gradual development of lower extremity edema over the past 2 to 3 months. He denied complaints of dysuria, polyuria, hematuria, or any discoloration of his urine. The remainder of the review of systems was unremarkable. A 2-dimensional echocardiogram revealed a normal size heart, normal valvular structure and function, and preserved left ventricular systolic function with a left ventricular ejection fraction of 55-60 percent. Relevant serological studies were conducted to evaluate the etiology of nephrosis. In addition to a urinalysis, the urine protein and creatinine were measured. Results from the urinalysis were positive for proteinuria (3+) and red blood cells (50-100 RBC's/ $\mathrm{HPF}$ ). The spot urine protein/creatinine ratio was 4.0. The patient's blood urea nitrogen (BUN) and serum creatinine were $17 \mathrm{mg} / \mathrm{dl}$ and $0.9 \mathrm{mg} / \mathrm{dl}$, respectively. Erythrocyte sedimentation rate was $72 \mathrm{~mm} / \mathrm{hr}$ with a normal complete blood count and differential. Serological tests for HIV (types I and II), HIV p24 antigen, Hepatitis A, B, and $\mathrm{C}$ titers were negative. Furthermore, tests for ANA, RPR, rheumatoid factor, c-ANCA, p-ANCA, cryoglobulin, lupus anticoagulant and anticardiolipin antibodies were negative. Both C3 and C4 complement levels were within nor- 


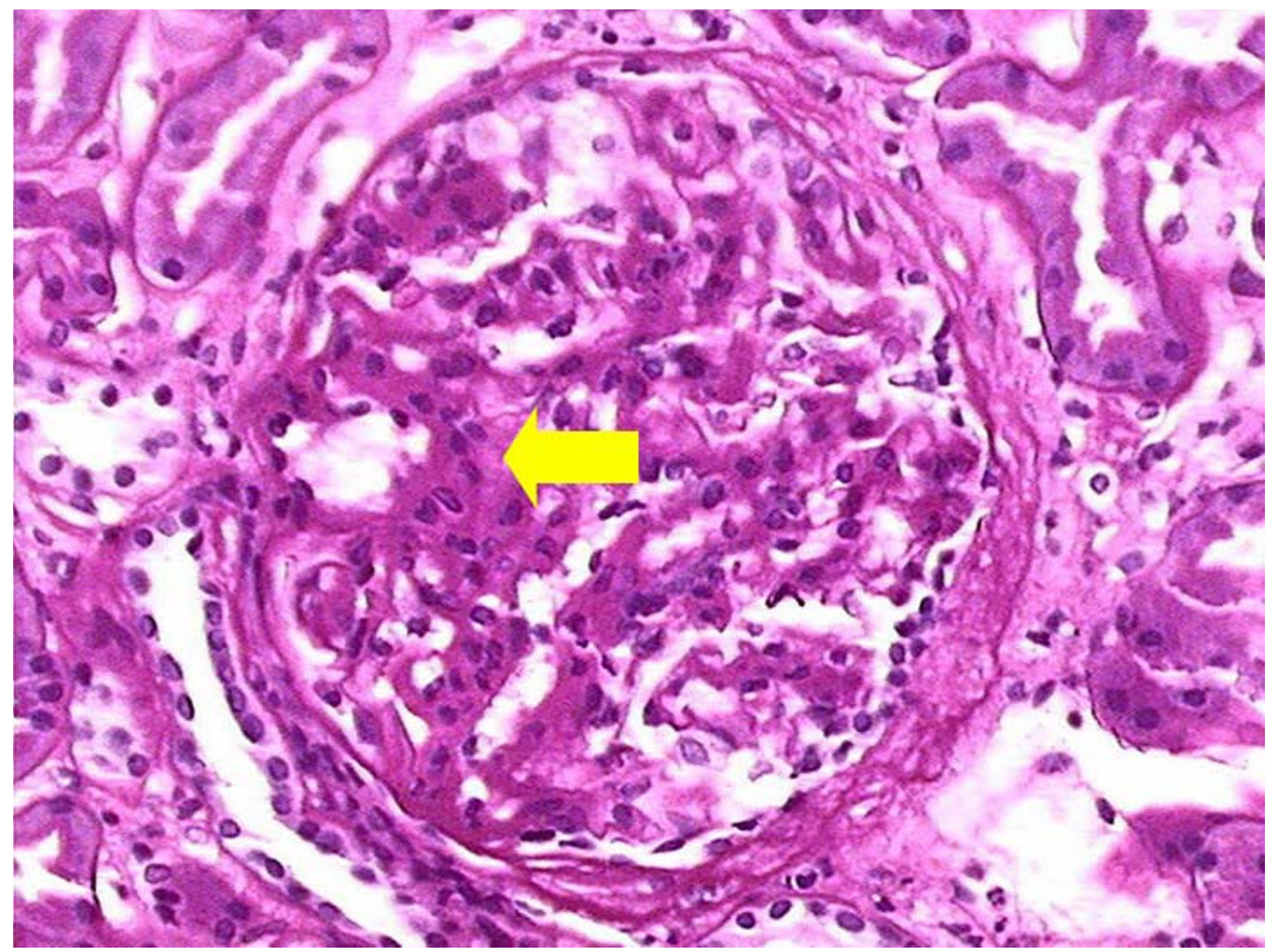

\section{Figure I}

Renal biopsy (Light Microscopy). Light microscopy image of a glomerulus demonstrating negative staining for both Congored and thioflavin-T. Expansion of the mesangium with increased hyalinization of the basement membrane (arrow) and thickening capillary loops is present.

mal limits. Additionally, serum protein electrophoresis was negative for a monoclonal gammopathy. The kappa/ lambda ratio was 1.93 (NML range: 1.47-2.95). Urine protein electrophoresis was also unremarkable without evidence of Bence-Jones proteins.

As a result of the clinical and diagnostic findings consistent with nephrotic syndrome, a renal biopsy was performed. Biopsy results demonstrated sclerosis of approximately one-third of the glomeruli. The remaining glomeruli were hypercellular, exhibiting both mesangial and epithelial hyperplasia. Deposition of homogenous eosinophilic material was noted in capillary walls and mesangial areas, and stains for Congo red, thioflavin $\mathrm{T}$ and amyloid AA protein were all negative. Direct immun- ofluorescence showed a linear pattern of staining for IgG and C3, with equal staining for kappa and lambda light chains. Electron microscopy showed accumulation of fibrillary material in mesangial areas and capillary basement membranes [Figures 1, 2]. The individual fibrils averaged 15-20 nm in diameter. In light of the noncongophilic staining and fibril size, a diagnosis of fibrillary glomerulonephritis was rendered.

\section{Discussion}

Once regarded simply as an inflammatory, autosomal recessive disease of unknown etiology, the spectrum of FMF has evolved as a complex genetic puzzle during the genomic era. More than forty missense mutations resulting in abnormal pyrin proteins have led to a new para- 


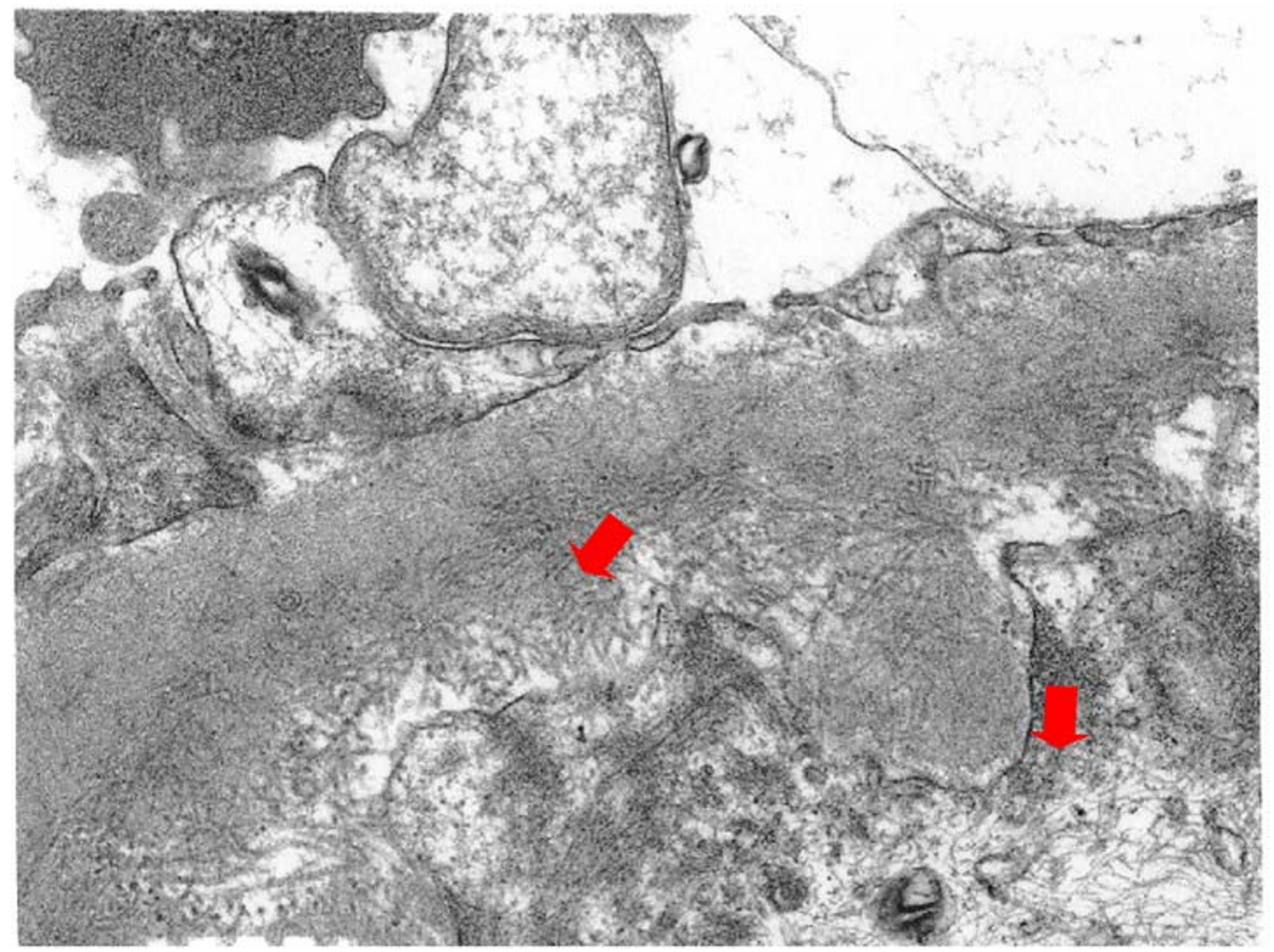

Figure 2

Fibrillary Glomerular Deposition (Electron Microscopy). Electron micrograph of renal biopsy showing randomly arranged microfibrils (asterisks) measuring $15-20 \mathrm{~nm}$ in diameter located in the basement membrane and mesangium.

digm for FMF as an inherited state of dysregulated inflammation. The altered gene products - the so-called pyrins - are fundamental to understanding FMF. Pyrincontaining proteins play a pivotal role in the immune response by serving as key inflammatory mediators. Unsurprisingly, pyrin is found in large quantities in neutrophils and released in response to inflammatory stimuli. Additionally, a recently discovered pyrin-like domain was found to exist at the amino-terminal of several proteins involved in cell-signaling pathways inherent to inflammation. One pyrin protein, belonging to a larger class of the pyrin domain family, is involved in the Nuclear Factorkappa B (NF-kB) cell-signaling pathway. Nuclear Factorkappa $\mathrm{B}$ is an important transcription factor involved in inflammation via its induction of pro-inflammatory gene products. In individuals with the "wild-type" MEFV gene, pyrin serves a key role in regulating the intensity of the inflammatory response. In contrast, individuals with one or more missense mutations at the MEFV locus produce a pyrin protein with altered or absent function. Consequently, the response to inflammation is altered. The resultant dysregulated inflammatory response often times exceeds physiologic parameters and is disproportionate to the insult. [18-22]

The inflammation of FMF may not only be characterized as dysregulated, but is also chronic and recurrent. Its severity and duration have been associated with the secondary development of amyloidosis (AA variety). The amyloid fibrils that lead to nephrotic syndrome in FMF 
are derived from a serum precursor, serum amyloid A (SAA), itself the result of chronic inflammation. Amyloidosis, with renal involvement and nephrotic syndrome, has become the expected complication of longterm FMF. [14-17]

The novel association between FMF and fibrillary glomerulopathy in this patient raises two contingent questions. First, is the association itself a chance one, but if it is not, is fibrillary glomerulopathy like amyloidosis the result of material deposition that reflects chronic, dysregulated inflammatory activity? The present state of knowledge regarding fibrillary glomerular diseases strongly suggests that the presence of fibrils in the glomeruli of affected individuals represents fibrillar derivation from circulating immunologic molecules, fragments, or immune complexes [14]. Since their etiology, deposition and structure are analogous to that of amyloid in FMF, it is highly intriguing to postulate that this patient's renal involvement is more than a chance occurrence. Prior disease associations with the fibrillary glomerulopathies involve the presence of immune response-associated products $[14,15]$. Future reports of individuals or kindred with FMF, nephrotic syndrome and fibrillary glomerulopathy will be required to substantiate our theory.

\section{MEFV GENE LOCUS}

(a)

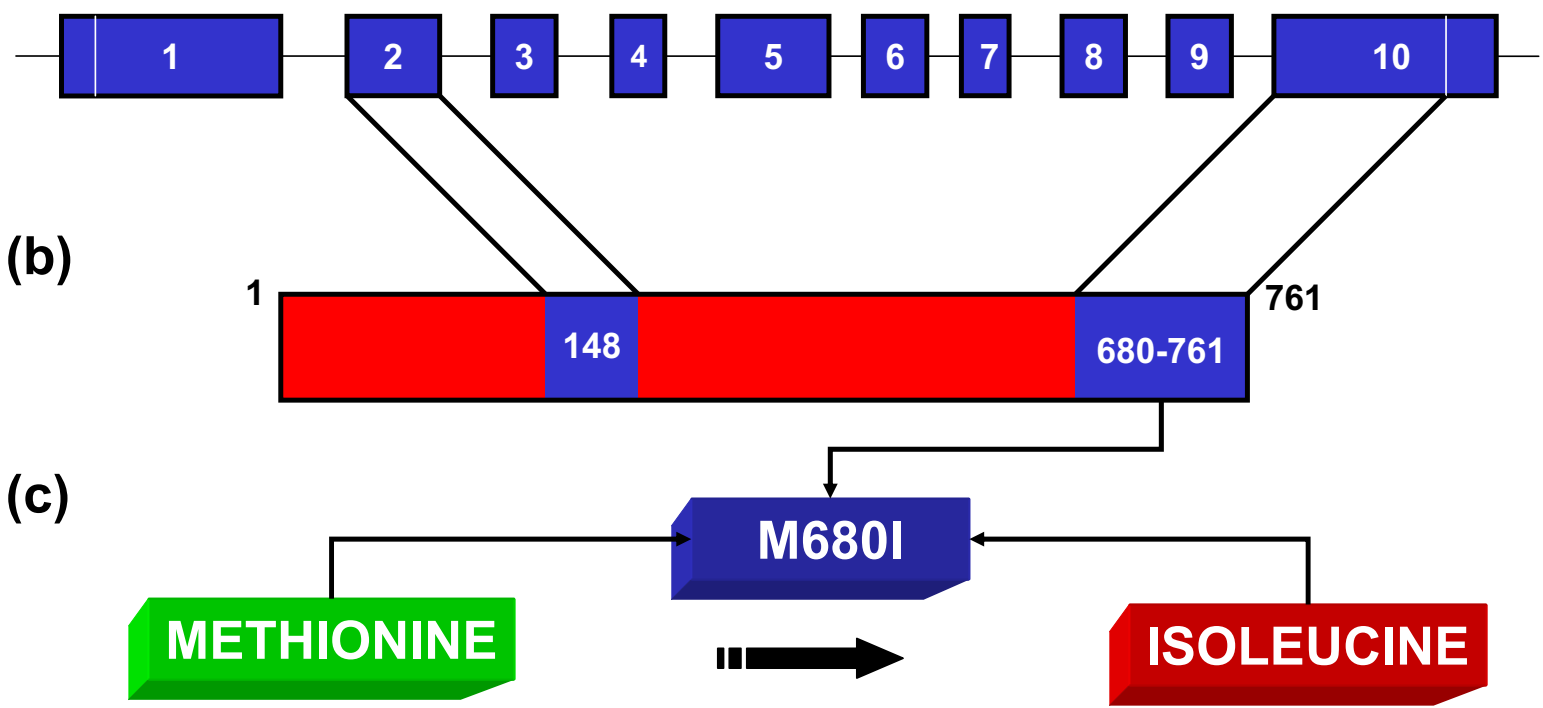

Amino Acid Substitution

\section{Figure 3}

M680I Missense Mutation. Illustration of the unspliced MEFV gene locus with exons I-I0 depicted (a), the spliced mRNA transcript revealing exon 2 and exon 10 and their respective codon number identifying where the nine most common mutations for FMF have been identified (b); a diagram illustrating the derivation of the M680I mutation from exon 10 with the amino acid methionine (wild-type) substituted with isoleucine at codon 680 (c). 


\section{Conclusions}

Although the association between chronic inflammation and amyloidosis (AA) is well known, the present description of fibrillary glomerulopathy in FMF requires further elucidation. Nevertheless, the new association among FMF, nephrotic syndrome, fibrillary glomerulopathy, and an M680I (Figure 3) heterozygous genotype may represent a novel renal complication of FMF. Furthermore, it is suggested that symptomatic heterozygous individuals may actually be compound heterozygotes for a mutation not yet identified [22]. As the number of MEFV mutations discovered continues to increase, more data will become available revealing further relationships among the many different MEFV missense mutations and their phenotypic expression in various ethnic groups.

\section{Competing interests}

None declared.

\section{Authors' contributions}

1. Dr. Patrick Fisher served as primary author of this manuscript. Furthermore, he served as primary care physician for the patient described in this manuscript. Additionally, he was also responsible for the clinical evaluation leading to the diagnosis of nephrotic syndrome and subsequent fibrillary glomerulonephritis. Furthermore, Dr. Fisher was responsible for preparation and revision of the manuscript.

2. Dr. L. Tammy Ho served a consulting role as the clinical attending nephrologist. She served a significant role in the clinical evaluation of the patient's nephrotic syndrome, including the performance of the renal biopsy. Furthermore, she assisted in providing her clinical expertise in manuscript preparation.

3. Dr. Robert Goldschmidt served as the clinical pathologist who evaluated the renal biopsy specimens. In addition, he was responsible for the pathological diagnosis of fibrillary glomerulonephritis. Furthermore, he contributed to the preparation of the manuscript, focusing on the description of the clinical pathology.

4. Dr. Ronald Semerdjian served a significant role through his contribution as the patient's former primary care physician. During this time, he made the initial clinical diagnosis of Familial Mediterranean Fever in our patient. He also contributed to the preparation of the manuscript through his careful review and contributions.

5. Dr. Gregory Rutecki played a significant role as a consultant nephrologist and contributed significantly to the preparation and the revision of this manuscript.

\section{Acknowledgements}

Written consent was obtained from the patient for publication of the patient's details. I would like to acknowledge this patient for his perseverance, motivation, and unrelenting will to overcome the many obstacles he has and will encounter in the future.

I would also like to acknowledge the following physicians:

Dr. Gabriel Berlint

Director, Outpatient Clinic for Adults and Children, Evanston Northwestern Healthcare, Evanston, IL

tFor his clinical wisdom and dedication to the care of this patient.

$\ddagger$ Mark Haas, MD, PhD

Associate Professor of Pathology, Director, Electron Microscopy Laboratory The Johns Hopkins University School of Medicine, Baltimore, MD

‡For his expert analysis of the renal biopsy specimens and confirmation of the diagnosis of fibrillary glomerulonephritis.

\section{References}

I. Sohar E, Merker HJ, Missmahl HP, Gafni J and Heller H: Electronmicroscope observations on peri-reticulin and peri-collagen amyloidosis in rectal biopsies. J Pathol Bacteriol 1967, 94:89-93.

2. Reiman H: Periodic disease. Probable syndrome including periodic fever. JAMA 1948, I36:239-244.

3. Matzner $Y$ : Biologic and clinical advances in familial mediterranean fever. Review of Oncology and Hematology 1995, I 8: 197-295.

4. Shohat M, Magel N, Shohat T, Chen X, Dagan T, Mimouni A, Danon Y, Lotan R, Ogur G, Sirin A, Schlezinger M, Halpern GJ, Schwabe A, Kastner D, Rotter JI and N F-G: Phenotype-genotype correlation in familial Mediterranean fever: evidence for an association between Met694Val and amyloidosis. Eur J Hum Genet 1999, 3:287-292.

5. Zemer DPM, Sohar E, Modan M, Cabili S and Gafni J: Colchicine in the prevention and treatment of the amyloidosis of familial Mediterranean fever. N Eng J Med I 986, 3 I 4: I00 I-I005.

6. Tekin M, Yalcinkaya F, Tumer N, Cakar N, Kocak H, Ozkaya N and Gencgonul H: Familial Mediterranean fever - renal involvement by diseases other than amyloid. Nephrol Dial Transplant 1999, 14:475-479.

7. Pras EAI, Gruberg L, Balow JE, Prosen L, Dean M, Steinberg AD, Pras $M$ and Kastner DL: Mapping of a gene causing familial Mediterranean fever to the short arm of chromosome 16. N Eng J Med 1992, 326:1509-1513.

8. A candidate gene for familial Mediterranean fever. The French FMF Consortium. Nat Genet 1997, I 7:25-3I.

9. Ancient missense mutations in a new member of the Ro-Ret gene family are likely to cause familial Mediterranean fever. The International FMF Consortium. Cell 1997, 90:797-807.

10. Pras M: Familial Mediterranean fever: from clinical syndrome to the cloning of the Pyrin gene. Scand J Rheumatol 1998, 27:92-97.

II. Mimouni A, Magal N, Stoffman N, Shohat T, Minasian A, Krasnov M, Halpern GJ, Rotter Jl, Fischel-Ghodsian N, Danon YL and Shohat M: Familial Mediterranean fever: effects of genotype and ethnicity on inflammatory attacks and amyloidosis. Pediatrics 2000, 105:E70.

12. Livneh A, Langevitz P, Zemer D, Zaks N, Kees S, Lidar T, Migdal A, Padeh $S$ and Pras M: Criteria for the diagnosis of familial Mediterranean fever. Arthritis Rheum 1997, 40:1879-1885.

13. Eisenberg S, Aksentijevich I, Deng Z, Kastner DL and Matzner YI: Diagnosis of familial Mediterranean fever by a molecular genetics method. Ann Intern Med 1998, 129:539-542.

14. Schwartz MM, Korbet SM and Lewis EJ: Immunotactoid Glomerulopathy. J Am Soc Nephrol 2002, I3:1390-1 397.

15. Korbet S, Schwartz S and Lewis E: The Fibrillary Glomerulopathies. Am J Kidney Dis 1994, 23:75 I-765. 
16. Iskandar SS, Falk RJ and Jennette JC: Clinical and pathologic features of fibrillary glomerulonephritis. Kidney Int 1992, 42: $140 \mid-1407$.

17. Mitchell A: Cell signalling: pyrin fever. Nat Rev Mol Cell Biol 2002, 3:150.

18. Guijarro $C$ and Egido J: Transcription factor-Kappa B (Nf-Kappa B) and renal disease. Kidney Int 200I, 59:4I5-424.

19. Ray A and Ray B: Persistent expression of serum amyloid A during experimentally induced chronic inflammatory condition in rabbit involves differential activation of SAF, NfKappa B, and C/Ebp transcription factors. J Immunol 1999, 163:2143-2150.

20. Lawrence T, Gilroy GW, Colville-Nash PR and Willoughby D: Possible new role for Nf-Kappa $B$ in the resolution of Inflammation. Nat Med 200I, 7:I29|-I 297.

2I. Manji G, Wang L, Geddes B, Brown M, Merriam S, Al-Garawi A, Mak $S$, Lora J, Briskin M, Jurman M, Cao J, DiStefano $P$ and Bertin J: PYPAFI, a PYRIN-containing ApafI-like protein that assembles with ASC and regulates activation of NF-Kappa B.J Biol Chem 2002, 277: II570-II575.

22. Livneh A, Langevitz P, Shinar Y, Zaks N, Kastner DL, Pras M and Pras $\mathrm{E}$ : MEFV mutation analysis in patients suffering from amyloidosis of familial Mediterranean fever. Amyloid 1999, 6: I-6.

\section{Pre-publication history}

The pre-publication history for this paper can be accessed here:

http://www.biomedcentral.com/1471-2369/4/6/prepub

Publish with Bio Med Central and every scientist can read your work free of charge

"BioMed Central will be the most significant development for disseminating the results of biomedical research in our lifetime. "

Sir Paul Nurse, Cancer Research UK

Your research papers will be:

- available free of charge to the entire biomedical community

- peer reviewed and published immediately upon acceptance

- cited in PubMed and archived on PubMed Central

- yours - you keep the copyright

Submit your manuscript here:

http://www.biomedcentral.com/info/publishing_adv.asp 